Deep Sea Research (1980)

26A, Suppl.1 (GATE)

\title{
INTRODUCTION TO A COLLECTION OF PAPERS ON GATE OCEANOGRAPHY AND SURFACE LAYER METEOROLOGY
}

\author{
G. Siedler and J. D. Woods \\ Institut für Meereskunde, Düsternbrooker Weg 20, $2300 \mathrm{Kiel}$, \\ Federal Republic of Germany
}

\begin{abstract}
A better understanding of tropical convection, being an essential part of the global atmospheric circulation, was considered crucial for an improvenent of weather prediction and climate modelling, the fundamental goals of the Global Atmospheric Research Programme GARP. The first major international field experiment within this programe was therefore performed in the tropics: GATE (GARP Atlantic Tropical Fxperiment) 1974. The basic objectives for GATE were (a) to provide a means of estimating the effects of smaller tropical weather systems on synoptic scale circulations and (b) to facilitate the development of numerical modelling and prediction methods (ICSU, wMO, 1974 a, see Appendix).
\end{abstract}

At the same time the experiment provided a unique opportunity for investigating the response of the tropical ocean to atmospheric forcing on various scales. The resulting oceanographic sub-programme was presented by SCOR/ICSU (1973) and ICSU/WMO (1974b), the atmospheric houndary layer sub-programme by ICSU/WMO (1973) (see Appendix). The oceanographic observations on the smaller scales were mostly performed in the Intertropical Convergence zone (ITCZ) while larger scale studies were concentrated on the equatorial region.

The two GATE supplements to Deep-Sea Research present results on the oceanic and atmospheric boundary layers in the region in or close to the ITCZ in the eastern Atlantic (Vol. I) and in the equatorial Atlantic (Vol. II). Most of the papers are based on lectures given at the SCOR/IAPSO/IAMAP "GATE Symposium on Occanography and surface Layer Meteorology", 16-20 May 1978, in Kiel. The manuscripts had to satisfy the requirements for Deep-Sea Research and went through the usual refereeing.

In order to provide some background material for the reader of the individual articles in this volume $I$, the basic objectives and the design of small- and mesoscale experiments will be summarized here. 
The dominant scales of tropical weather systems determined the distribution of most research vessels in GATE:

Scale A: Easterly waves, $10^{3}-10^{4} \mathrm{~km}$
Scale B: Cloud clusters, $10^{2}-10^{3} \mathrm{~km}$
Scale C: Mesoscale, $10^{1}-10^{2} \mathrm{~km}$
Scale D: Hot towers, $10^{0}-10^{1} \mathrm{~km}$

The A-scale measurements covered the whole tropical Atlantic between $10^{\circ} \mathrm{S}$ and $20^{\circ} \mathrm{N}$ with a specific equatorial sub-programme (fig. 1). The $\mathrm{B} / \mathrm{C} / \mathrm{D}$ scale observations were centred at the expected position of the ITCz half way between the equator and the cape Verde Islands. The three-month duration of GATE included three observational phases, each three weeks long (fig. 2). The ships in each phase are presented in fig. 3 and table 1 . The C-scale ship and buoy array nested in the B-scale array during phase III is plotted in fig. 4.

The atmospheric boundary layer studies at the ITCZ were supposed to describe low-level mass and moisture convergence and vertical fluxes of sensible heat, momentum and water vapor from the sea surface upwards. The area in the open Atlantic $1000 \mathrm{~km}$ south-west of the aircraft base at Dakar presented a satisfactory variety of disturbed and undisturbed conditions in the atmospheric boundary layer. The main emphasis in the meteorological programmes was put on identifying the above processes and on their parameterization for the modelling of the tropical convection.

Most of the oceanographic investigations at the ITCZ were designed to study the response of the upper occan to atmospheric forcing. The site and the ship array proved less than ideal for the exploration of the oceanic boundary layer, since they lay in the swiftly flowing Equatorial countercurrent, which swept water through the $100 \mathrm{~km}$ array in three days, with the advective term, rather than the vertical turbulent transport term, dominating the heat budget equation. Furthermore, significant patchiness existed in"mixed layer" salinity on a scale equivalent to less than one day's advection distance. Chances were therefore low of relating Eulerian time series of thermohaline profiles from individual fixed ships to one-dimensional models of the oceanic boundary layer. The main aim of the oceanographic programme was to identify the dominant processes that distribute energy and momentum in this part of the Atlantic. Specific phenomena studied were surface and internal waves, mixed layer changes, mean current and shear, and oceanic fronts at the shallow boundary layer existing in this area.

The standard meteorological observations on the GATE ships included measurements with tethered balloons at constant levels and vertical profiling systems, and surface flux measurements made either on board the ship or on a nearby buoy. The oceanographic observations were made on ships by conductivity -temperaturedepth profiling devices, water samplers with reversing thermometers, mechanical or expendable bathythermographs and current profiling sondes. Moored buoy systems were used to obtain surface meteorological observations and upper ocean currents and temperature. These measurements on fixed position were supplemented by mobile ship observations with towed devices scanning the upper ocean and by additional special observations of individual research groups. A detailed summary of the field phase operations is presented in ICSU, wo (1975) (see Appendix). Further details on some of the more specialized measurements can be found in several of the following articles.

We hope that by bringing together in these two volumes a large part of the papers that resulted from the GATE oceanographic and atmospheric boundary layer 
programes we will be able to make the results more easily accessible for those who are interested in tropical processes and their role with respect to weather and climate modelling.

\section{ACKNOWLEDGMENTS}

We would like to use this opportunity to thank the numerous individuals and international and national institutions making this research programme and the publishing of these volumes possible. The symposium forming the basis of this publication was organized by the scientific Committee on Oceanic Research (SCOR), the International Association for the Physical Sciences of the Ocean (IAPSO) and the International Association of Meteorology and Atmospheric Physics (IAMAP) in cooperation with the world Meteorological organization (wio), the Intergovernmental oceanographic Commission (IOC) of UNESCO and the German Meteorological Society (DMG), with specific support by the Deutsche Forschungsgemeinschaft. We arprecjated their assistence.

\section{ARPENDIX}

\section{Selectea remorts on GATE}

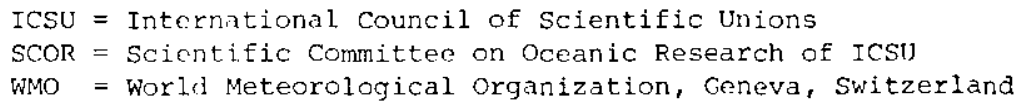

SCOR, ICSU (1973). SCOR proposal for a GATE Oceanographic Progran, pp. 49.

ICSU, WMO (1973). The boundary-layer sub-programme for the GARP Atlantic Tropical Fxperiment. GATE Report No. 5, ep. 128.

ICSU, WMO (1974a). The central programme for the GARP Atlantic Tropical Exprriment. GATE Report No. 3, pp. 35.

ICSU, WMO (1974b). The oceanographic sub-programme for the GARP Atlantic Tropical Experiment. GATE Report No. 8, pp. 135.

ICSU, W:10 (1375). Report on the field phase of the GARP Atlantic Tropical Experiment operations. GATE Report No. 15, pp. 148.

ICSU, wro (1979). The GATE Bibliography, pp. 35.

ICSU, WMO (1979). Final report of sCoR working Group 43 on oceanography related to CATE, PP. 58. 


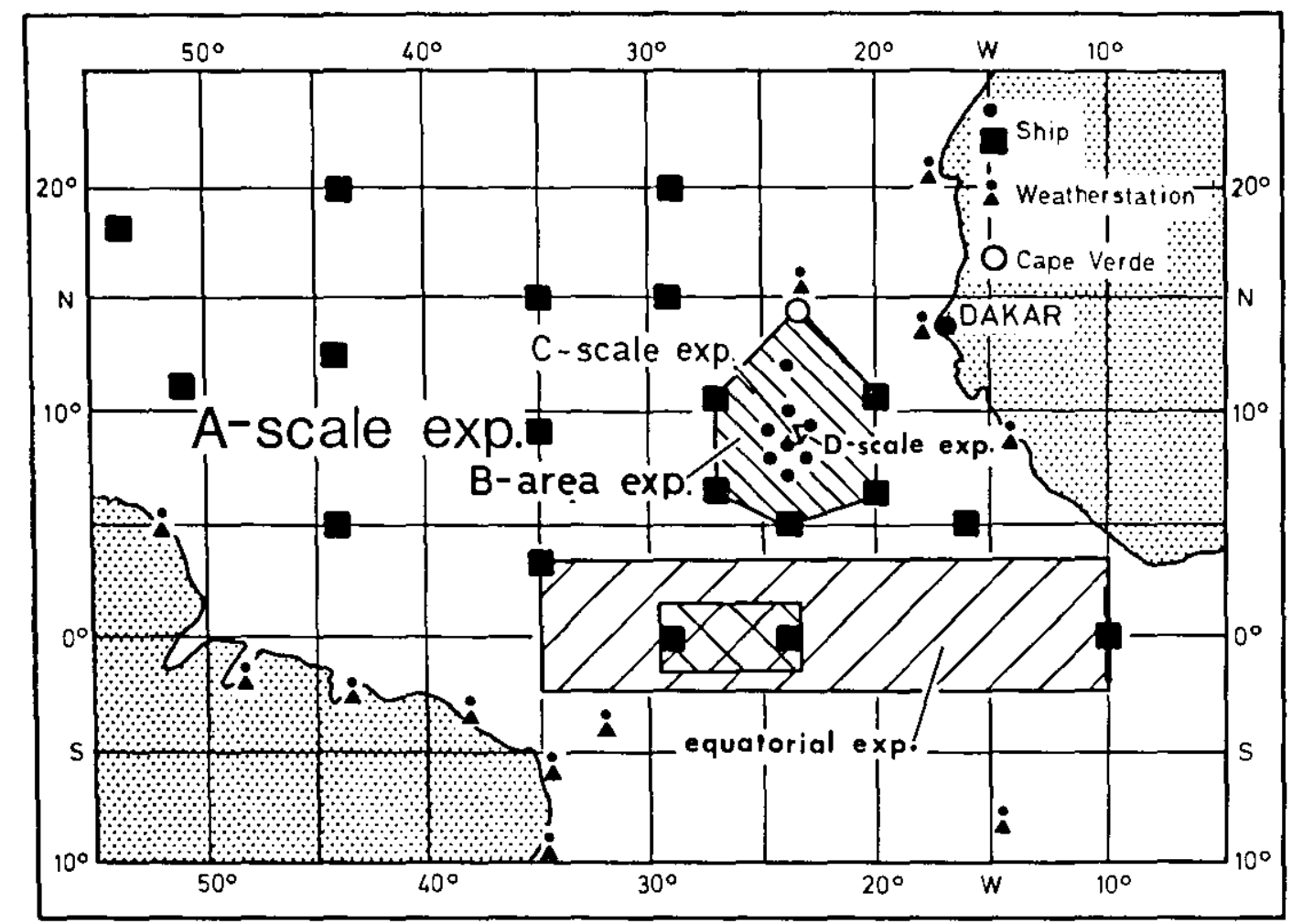

Fig. 1. Map indicating GATE observational areas in the tropical Atlantic, covering dominant scales $A$ to $D$ as defined in the text. 


EPHASE $I \rightarrow-1$
1974 June

Fig. 2. GATE schedule. Specific experiments with intense oceanographic observations are indicated. 


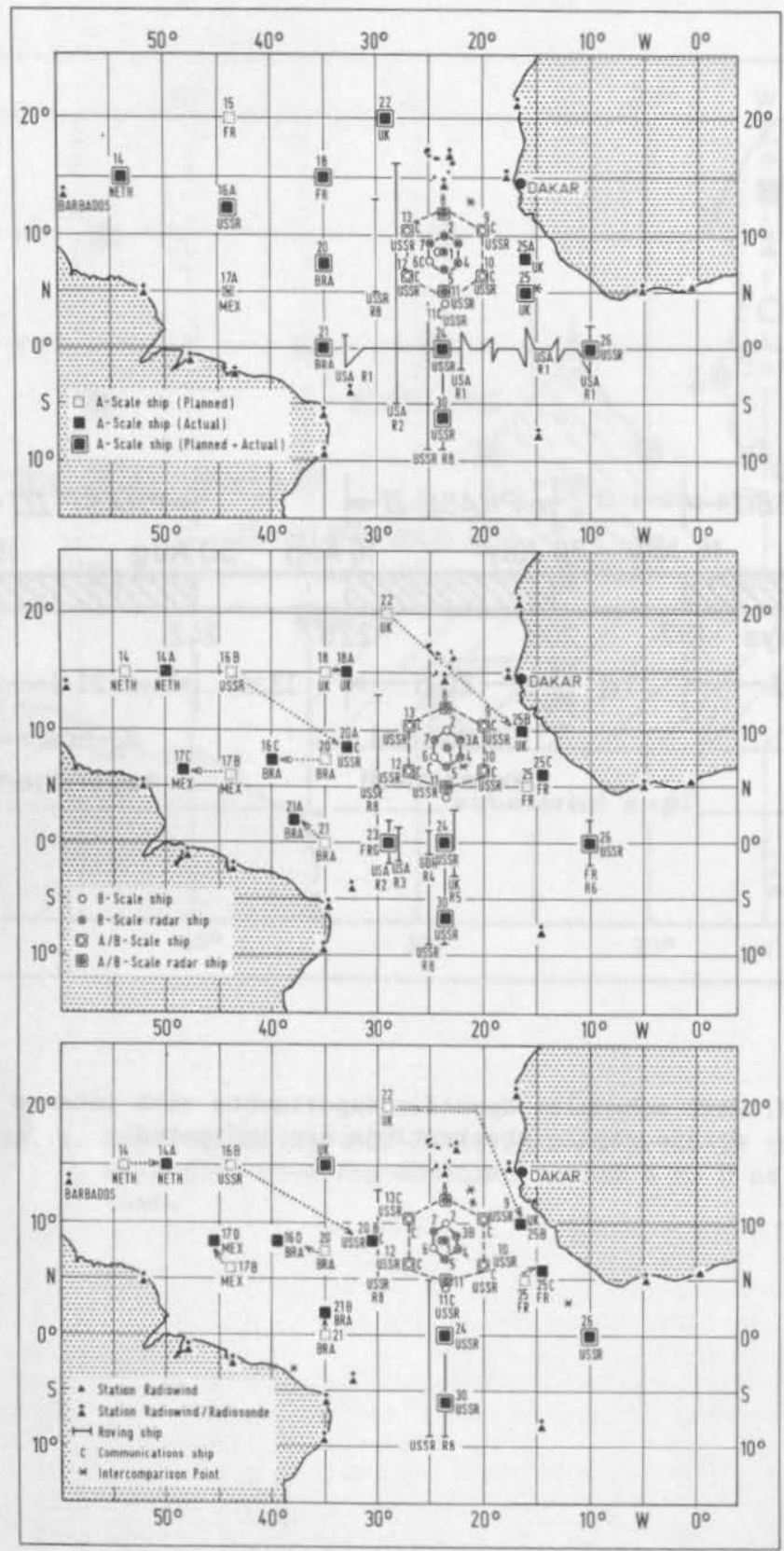

Fig. 3. Ship distribution during the three phases of GATE (see also Table 1). 
TABLE 1 Positions of ships (see Fig. 3) during the three phases of GATE.

Position No.

Ship

Position No.

Ship

\begin{tabular}{|c|c|c|c|c|c|c|c|}
\hline \multicolumn{3}{|c|}{ Phases } & & \multicolumn{3}{|c|}{ Phases } & \\
\hline I & II & III & & I & II & III & \\
\hline & & 6 & BIDASSOA & 18 & & & CHARCOT \\
\hline 1 & 1 & 4 & OCEANOGRAPHER & 20 & $16 \mathrm{C}$ & $16 \mathrm{D}$ & SIRIUS \\
\hline 4 & 4 & 1 & METEOR & 21 & $21 \mathrm{~A}$ & $21 B$ & AL. SALDANHA \\
\hline $1 \mathrm{~A}$ & 2 & 2 & VANGUARD & 22 & $25 B$ & $25 B$ & ENDURER \\
\hline 2 & $1 \mathrm{~A}$ & $1 \mathrm{~A}$ & PROF. VIZE & & 23 & & ANTON DOHRN \\
\hline $3 \mathrm{~A}$ & $3 A$ & $3 C$ & ¿UADRA & 24 & 24 & 24 & ACAD. KURCHATOV \\
\hline 5 & 5 & 5 & RESEARCHER & 25 & $18 \mathrm{~A}$ & 18 & CHARTERER \\
\hline 6 & 6 & 28 & DALLAS & & $25 C$ & & LA PERLE \\
\hline 7 & 7 & 7 & GILLISS & & R6 & $25 \mathrm{C}$ & CAPRICORNE \\
\hline 8 & 8 & 8 & ACAD. KOROLOV & 26 & 26 & 26 & PASSAT \\
\hline 9 & 9 & 9 & PORYV & & & 27 & PLANET \\
\hline 10 & 10 & 10 & ERNEST KRENKEL & & & 29 & HECLA \\
\hline 11 & 11 & 11 & PROF. ZUBOV & 30 & 30 & 30 & LOMONOSOV \\
\hline $11 \mathrm{C}$ & $11 \mathrm{C}$ & $11 \mathrm{C}$ & MUSSON & & R7 & $28 \mathrm{~A}$ & H.J.W. FAY \\
\hline 12 & 12 & 12 & OKEAN & R1 & R1 & & ATLANTIS II \\
\hline 13 & 13 & 13 & PRIBOY & R2 & R2 & R2 & TRIDENT \\
\hline 14 & $14 \mathrm{~A}$ & $14 \mathrm{~A}$ & ONVERSAAGD & & R3 & R3 & COL. ISELIN \\
\hline 15 & & & M. DUFRESNE & & R4 & & A.V. HUMBOLDT \\
\hline $16 \mathrm{~A}$ & $20 A$ & $2 \mathrm{OB}$ & VOLNA & & R5 & R5 & DISCOVERY \\
\hline $17 \mathrm{~A}$ & $17 \mathrm{C}$ & $17 \mathrm{D}$ & MATAMOROS & R8 & R8 & R8 & S. DEZHNEV \\
\hline
\end{tabular}




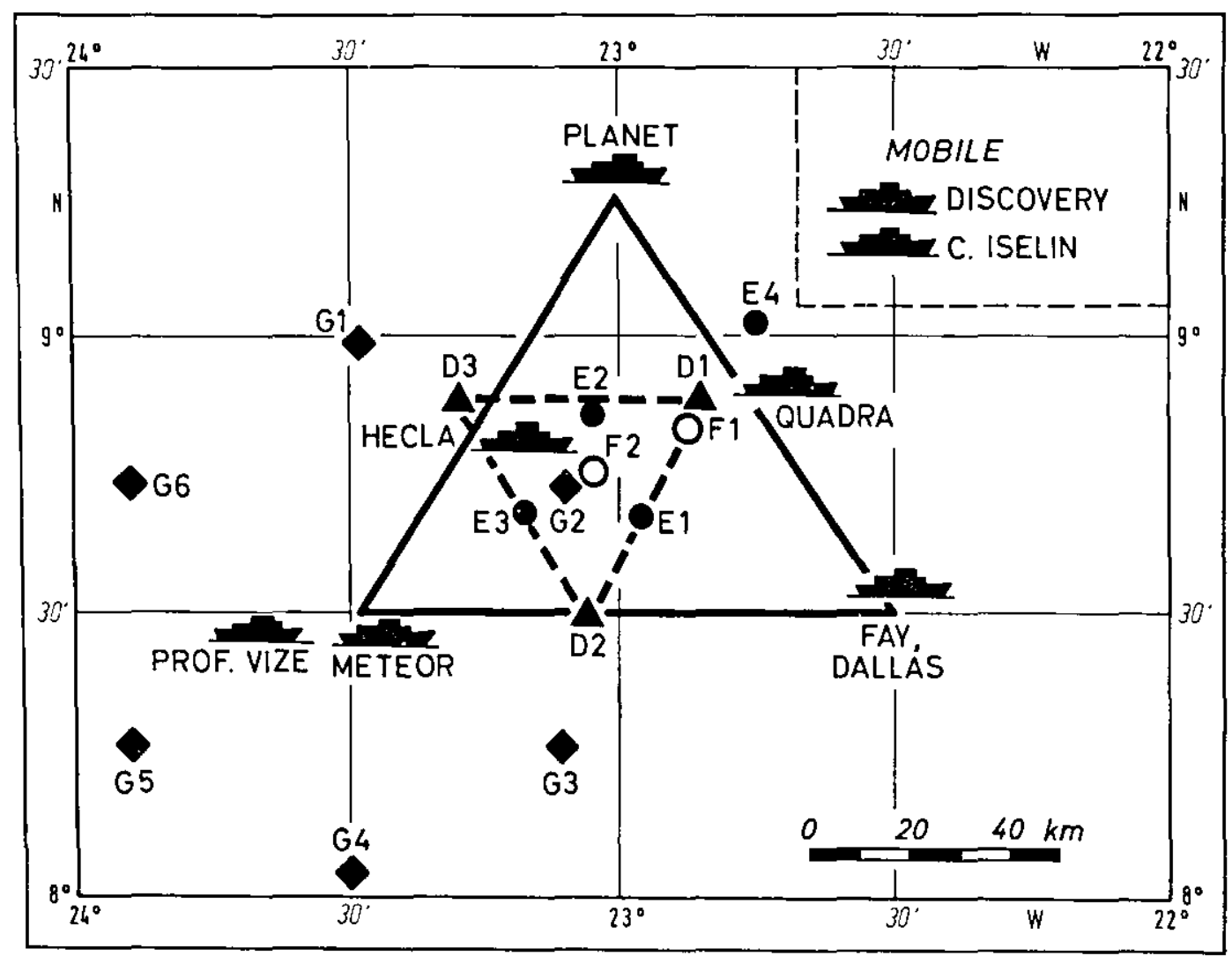

Fig. 4. C-scale ship and buoy array during phase III. 